\title{
Understanding genetic progression of squamous cell carcinoma to spindle cell carcinoma in a mouse model of head and neck cancer
}

\author{
RITA CHUANG and DAVID L. CROWE
}

\author{
University of Illinois Cancer Center, Room 530C, MC860, 801 S. Paulina Street, Chicago, IL 60612, USA
}

Received January 25, 2007; Accepted March 1, 2007

\begin{abstract}
Reports have suggested that spindle cell carcinoma of the head and neck occurs following radiation therapy of incompletely resected SCC, representing anaplastic progression of the primary tumor. Examination of differences between spindle cell carcinoma and SCC may provide important information about anaplastic progression, clinical behavior, and response to therapy. We created a mouse model that developed spindle cell carcinoma. Spindle cell carcinoma was characterized by marked downregulation of epithelial differentiation markers and cell adhesion genes. Expression of growth factors and receptors important for epithelial proliferation was inhibited while those which regulate fibroblast and mesenchymal cell proliferation were increased. By far the largest class of upregulated genes in spindle cell carcinomas was chemokine receptors and ligands which are involved in tumor cell invasion and metastasis. These changes in gene expression clearly show loss of epithelial characteristics, acquisition of mesenchymal phenotypes, and increased propensity for invasion and metastasis by spindle cell carcinomas.
\end{abstract}

\section{Introduction}

Squamous cell carcinoma of the head and neck (HNSCC) is the sixth most frequent cancer worldwide (1). HNSCC is a major cause of morbidity and mortality in developing nations, comprising up to $50 \%$ of all malignancies. HNSCC is the most common malignant tumor of the oral cavity with nearly 30,000 new cases and 8,000 deaths reported in the United States each year (2). Tobacco carcinogens are the primary etiologic agents of the disease with age and genetic background as contributory factors. The overall 5-year survival rate of approximately $50 \%$ has not changed significantly in recent decades.

A recent report identified a shortage of suitable animal models with which to study different biological and clinical

Correspondence to: Dr David L. Crowe, University of Illinois Cancer Center, Room 530C, MC860, 801 S. Paulina Street, Chicago, IL 60612, USA

E-mail: dlcrowe@uic.edu

Key words: differentiation, chemokines, proteinase inhibitors, epithelial-mesenchymal transformation, growth factors aspects of HNSCC (3). Because HNSCC is largely acquired by environmental carcinogen exposure rather than through germline mutations, there are no known familial forms of the disease in humans nor are there inbred rodent strains prone to spontaneous head and neck tumors (4). A classical animal model of HNSCC was carcinogen exposure of the hamster buccal cheek pouch (5). A second model of HNSCC relied on human tumor cell xenografts in immunodeficient mice. Studies using this model subcutaneously injected cultured human HNSCC cells into the backs of nude mice (6). These models have been used in many types of cancer to determine in vivo tumorigenicity but typically fail to replicate local invasion and lymph node metastasis of HNSCC. Variations on this model have injected human tumor cells into other anatomic sites $(7,8)$. However, the xenograft models are limited to human cancer cell lines that can adapt to the murine environment and do not replicate the early stages of carcinogenesis. A transgenic mouse model expressing activated K-ras reportedly developed epithelial lesions ranging from oral papillomas (9) to squamous cell carcinomas of skin, esophagus, stomach, uterine cervix, oral mucosa, and salivary glands (10). However, K-ras is reported to be infrequently mutated in human HNSCC cases $(11,12)$.

Spindle cell carcinoma of the head and neck is believed to be a rare variant of squamous cell carcinoma. Previous reports have suggested that spindle cell carcinoma occurs following radiation therapy of incompletely resected SCC, representing anaplastic progression of the primary tumor (13). Spindle cell carcinoma was present in $40 \%$ of recurrent tumors following treatment when it was not noted in the original tumor (14). Spindle cell carcinoma is believed to be a distinct histopathologic entity with both monophasic and biphasic patterns. Biphasic spindle cell carcinomas have been shown to express keratin in the spindle cell component (15). These tumors also expressed the fibroblast marker vimentin but were S100 negative (16). Previous studies have suggested that these tumors are aggressive, with 2-year survival rates of $30 \%$ (17). Prognostic factors included patient age and size of the primary tumor but not the degree of cervical lymph node involvement. Clinical responses to chemotherapy regimens were reported to be $50 \%$ (18).

Little is known about the genetic differences between SCC and spindle cell carcinoma. Examination of these differences may provide important information about anaplastic progression, clinical behavior, and response to chemotherapy. Due to the small number of available human cases of spindle 
cell carcinoma, we created a mouse model that developed spindle cell carcinoma in $10 \%$ of experimental animals. When the expression of gene products commonly altered in human SCC was assessed, spindle cell carcinomas showed dramatic differences when compared to mouse and human SCC. Using global gene expression profiling, spindle cell carcinomas notably demonstrated loss of stratified epithelial gene expression and upregulation of chemokine receptors and ligands. These studies highlight for the first time important differences between SCC and spindle cell carcinoma that may be important to human cancer.

\section{Materials and methods}

Mouse procedures. This study was approved by the Institutional Animal Care and Use Committee before any experiments were performed. C57B16J mice were housed in approved environmentally controlled facilities on 12-h light-dark cycles and unlimited access to food and water. Twenty-eight male and female mice were dosed orally twice weekly with $25 \mu \mathrm{g}$ dimethylbenzanthracene (DMBA) dissolved in $20 \mu 1$ ethanol. The time course and number of tumors were recorded for each animal. Mice were euthanized when any institutional criterion for experimental neoplasia in rodents was met. Euthanized mice were photographed and complete necropsies performed. A portion of each tumor specimen was flash frozen in liquid nitrogen or fixed in $4 \%$ buffered formaldehyde for $16 \mathrm{~h}$ at room temperature.

Histopathology and immunohistochemistry. Tumor tissue was dehydrated in an ethanol series, cleared in xylene, and embedded in paraffin. Five $\mu \mathrm{m}$ sections were prepared and mounted on poly-L-lysine coated slides. Representative sections were stained with hematoxylin and eosin and histologically evaluated by a pathologist. Immunohistochemical analysis was performed using a commercially available kit (Invitrogen, Carlsbad, CA). Sections were incubated at $60^{\circ} \mathrm{C}$ for $30 \mathrm{~min}$ and deparaffinized in xylene. Endogenous peroxidase activity was quenched by incubation in 9:1 methanol: $30 \%$ hydrogen peroxide for $10 \mathrm{~min}$ at room temperature. Sections were rehydrated in phosphate-buffered saline (PBS, $\mathrm{pH}$ 7.4) for $10 \mathrm{~min}$ at room temperature. Sections were blocked with $10 \%$ normal serum for $10 \mathrm{~min}$ at room temperature followed by incubation with anti-p53, met, c-myc, TERT, EGFR, cyclin A, cyclin B, cyclin E, TGF $\alpha, \mathrm{HGF}$, and PCNA antibodies (Santa Cruz Biotechnology, Santa Cruz, CA) for $16 \mathrm{~h}$ at room temperature. After washing three times in PBS, the sections were incubated with secondary antibody conjugated to biotin for $10 \mathrm{~min}$ at room temperature. After additional washing in PBS, the sections were incubated with streptavidin conjugated horseradish peroxidase enzyme for $10 \mathrm{~min}$ at room temperature. Following final washes in PBS, antigenantibody complexes were detected by incubation with hydrogen peroxide substrate solution containing aminoethylcarbazole chromogen reagent. Slides were rinsed in distilled water, coverslipped using aqueous mounting medium, and allowed to dry at room temperature. The relative intensities of the completed immunohistochemical reactions were evaluated using light microscopy by independent trained observers who were unaware of the mouse genotypes. A scale of 0-3 was used to score relative intensity, with 0 corresponding to no detectable immunoreactivity and 1,2, and 3 equivalent to low, moderate, and high staining respectively. Non-parametric data was analyzed by Fisher's exact test.

RNA extraction and gene expression profiling. Total RNA was extracted from microdissected primary tumor tissue using a commercially available kit (RNasy, Qiagen, Valencia, CA). Three independent samples from each group (well-, moderate-, and poorly-differentiated/spindle cell) were used in this gene expression analysis. The integrity of ribosomal RNA bands was confirmed by Northern gel electrophoresis. Total RNA $(10 \mu \mathrm{g})$ with spike in controls was first reverse-transcribed using a T7-oligo(dT) promoter primer in the first-strand cDNA synthesis reaction. Following RNase H-mediated secondstrand cDNA synthesis, the double-stranded cDNA was purified and served as a template in the subsequent in vitro transcription (IVT) reaction. The IVT reaction was carried out in the presence of T7 RNA polymerase and a biotinylated nucleotide analog/ribonucleotide mix for complementary RNA (cRNA) amplification and biotin labeling. The biotinylated cRNA targets were then purified, fragmented, and hybridized to Affymetrix GeneChip expression arrays (Santa Clara, CA). The murine genome 4302.0 microarray was used to interrogate 39,000 possible transcripts in each sample. After washing, hybridization signals were detected using streptavidin conjugated phycoerythrin. Affymetrix GCOS software was used to generate raw gene expression scores and normalized to the relative hybridization signal from each experiment. All gene expression scores were set to a minimum value of 2 times the background determined by GCOS software in order to minimize noise associated with less robust measurements of rare transcripts. Normalized gene expression data were imported into dChip software (http://www.biostat.harvard. edu/complab/dchip) for hierarchical clustering analysis using the average linkage algorithm. Raw data were analyzed for quality control and the significance of differential gene expression determined by t-test $(\mathrm{p}<0.05)$ and ratio analysis (>2-fold).

\section{Results}

All mice $(n=28)$ treated with twice weekly doses of DMBA developed papillomas after mean 22 weeks induction on the labial and buccal mucosa which grew larger and progressed to large tumors in the absence of additional induction. Mice developed euthanasia criteria with mean time course of 13 weeks after onset of tumors. The most common criterion was weight loss followed by tumor size. The gross appearance of well-differentiated SCC, moderately-differentiated SCC, and spindle cell carcinoma arising from the labial mucosa in the mouse model is shown in Fig. 1.

Histopathologic analysis of primary tumors from this model is shown in Fig. 2. At necropsy, the advanced stage HNSCCs showed clear evidence of tumor progression with all degrees of differentiation represented. Well-differentiated SCC was the predominant histologic type in 18 of 28 tumors examined by histopathology (64\%; Fig. 2A). These tumors demonstrated extensive basal layer and suprabasal differentiation with evidence of basement membrane formation and prominent 

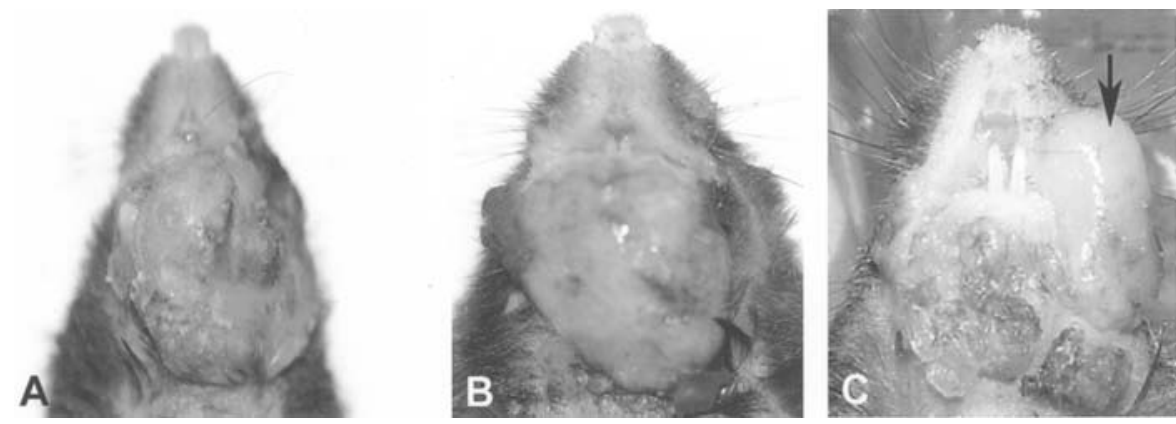

Figure 1. Gross appearance of (A), well-differentiated SCC; (B), moderately-differentiated SCC; and (C), spindle cell carcinoma 12 weeks after initial appearance. Note that the spindle cell carcinoma (arrow) was adjacent to two smaller well-differentiated tumors.
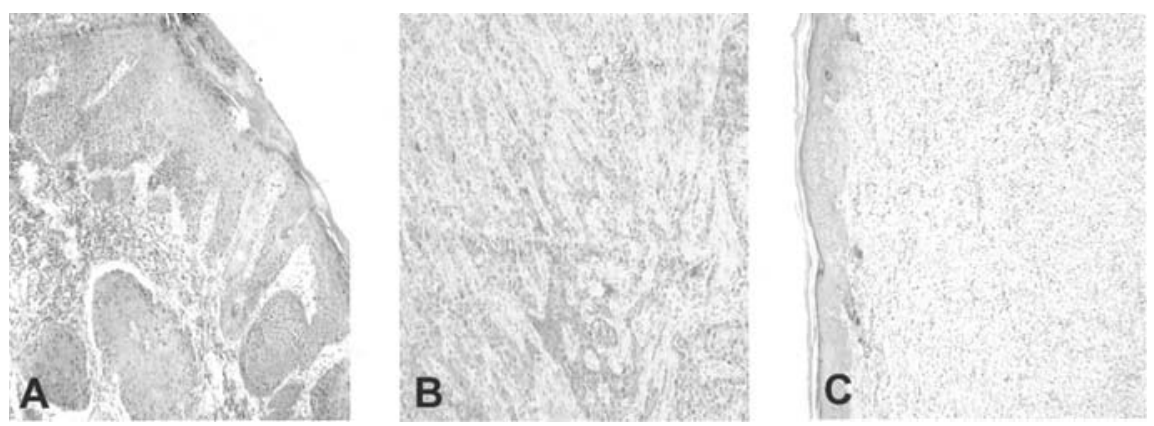

Figure 2. All stages of histopathologic differentiation are represented in the mouse model. (A), A well-differentiated HNSCC is shown. Note evidence of suprabasal differentiation and abundant abnormal keratinization. Magnification x100. (B), A moderately-differentiated HNSCC is shown. Note poorly developed intercellular junctions, abnormal keratinization, and lack of suprabasal differentiation. Magnification x100. (C), Poorly-differentiated spindle cell carcinoma. Note complete lack of epithelial characteristics and obliteration of normal submucosal structures. Magnification x100. The tumor is composed of basophilic spindle shaped cells with elongated nuclei. The spindle cells are organized into sheets and bundles. Note the presence of rare keratinized cells.

keratinization. Seven tumors were histopathologically classified as moderately-differentiated (25\%; Fig. 2B). These tumors showed less evidence of stratification, basement membrane production, and keratin formation. These carcinomas were also characterized by loss of intercellular junctions, increased nuclear/cytoplasmic ratio, nuclear pleiomorphism, and occasional mitotic figures. Three tumors were classified as poorly-differentiated or anaplastic (11\%; Fig. 2C). These tumors were composed of sheets and bundles of spindle shaped cells with elongated nuclei and complete loss of intercellular junctions. Eosinophilic inclusions were frequently observed in the cytoplasm of these cells which likely represented abnormal keratin production; mitotic figures were rarely observed in these tumors. These results indicate that the mouse HNSCC model can recapitulate the full histopathologic spectrum of tumors found in the human disease.

Our previous studies of human SCC showed that cyclin overexpression was a common feature of these tumors (19). To determine if these alterations in gene expression were observed in spindle cell carcinoma, we performed immunohistochemistry on these cancers and compared the results to those obtained in mouse SCC. As shown in Fig. 3, SCCs overexpressed cyclins A, B, and E as shown by immunohistochemistry. Approximately 50\% of SCCs overexpressed cyclin A compared to none of the spindle cell carcinomas $(\mathrm{p}<0.02)$. Approximately $60 \%$ of SCCs overexpressed cyclin B while this protein was not detected in any of the spindle cell carcinomas $(\mathrm{p}<0.006)$. Approximately $40 \%$ overexpressed

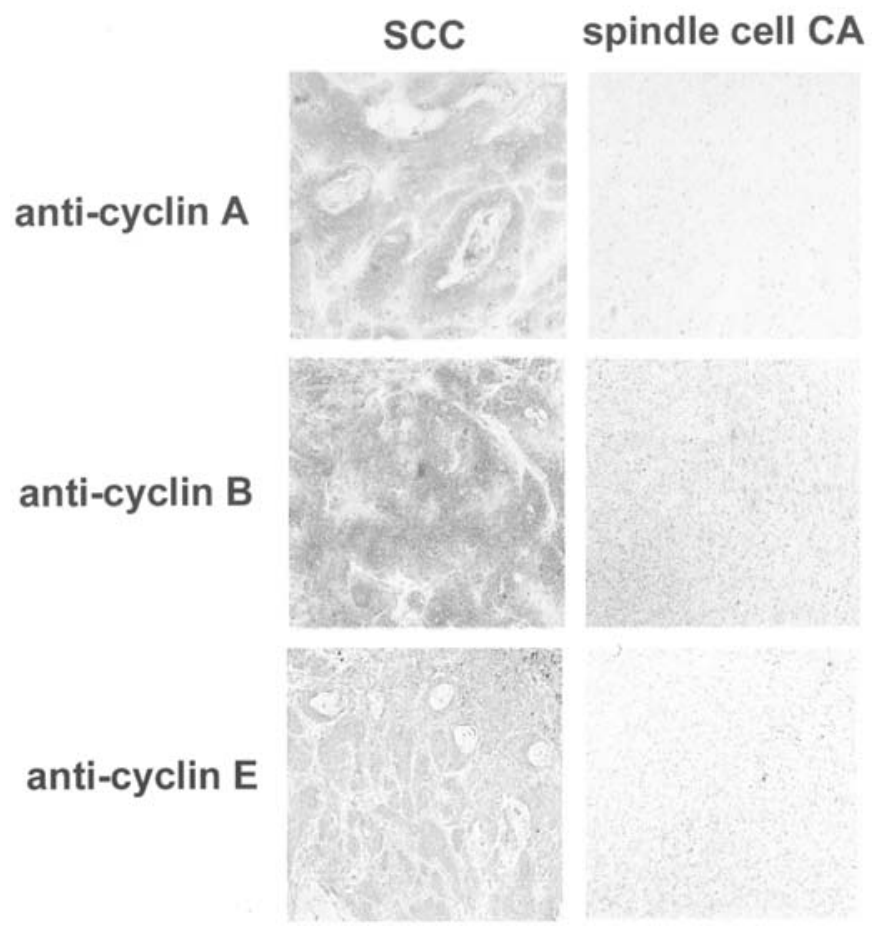

Figure 3. Loss of cell cycle regulatory protein expression in spindle cell carcinoma. Expression of cyclin A, cyclin B, and cyclin E in well-differentiated SCC and spindle cell carcinoma (CA) is shown by immunohistochemistry. These experiments were performed three times with different SCC and spindle cell carcinoma samples with similar results. Representative sections are shown. 


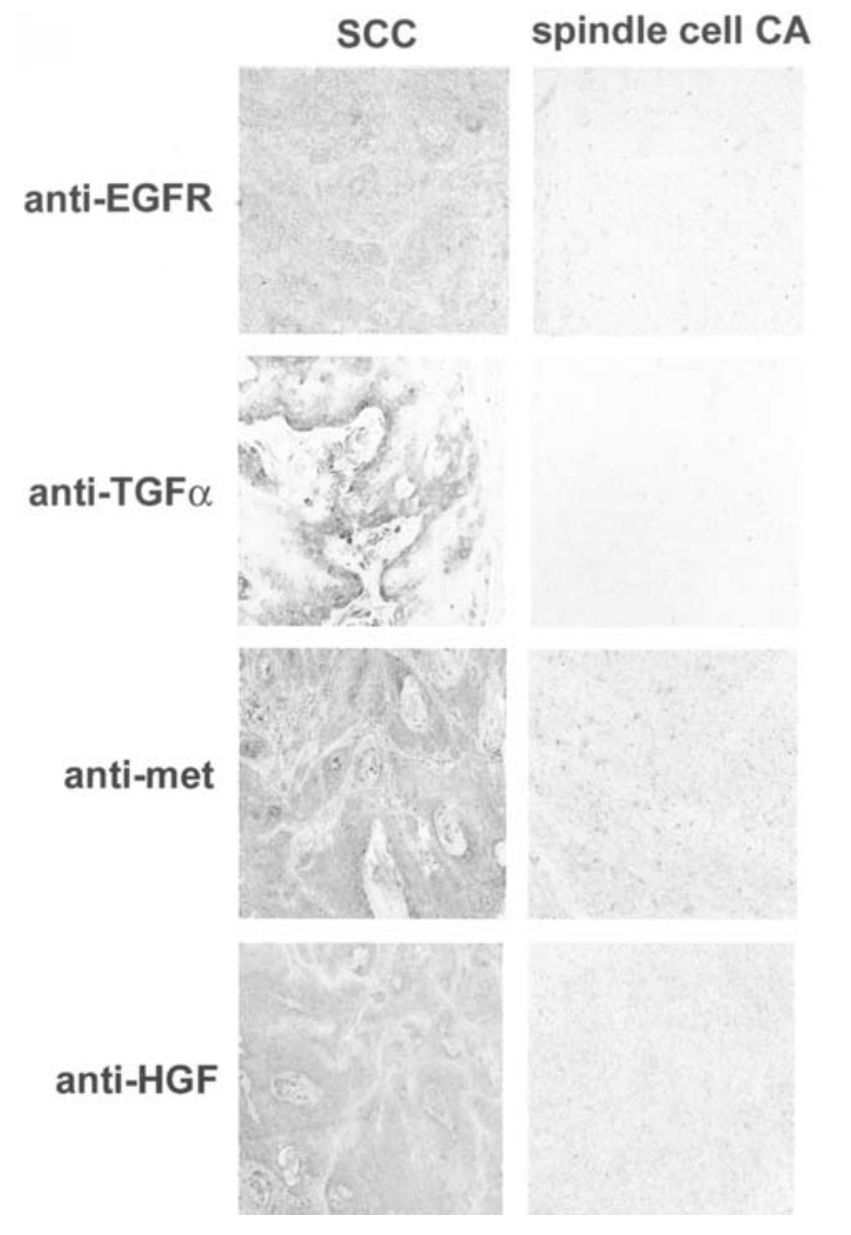

Figure 4. Loss of growth factor and receptor protein expression in spindle cell carcinoma. Expression of EGFR, TGF $\alpha$, met, and HGF in well-differentiated SCC and spindle cell carcinoma (CA) is shown by immunohistochemistry. These experiments were performed three times with different SCC and spindle cell carcinoma samples with similar results. Representative sections are shown.

cyclin E protein compared to none of the spindle cell carcinomas $(p<0.01)$. These results indicate that loss of cell cycle regulatory protein expression is a consistent feature of spindle cell carcinoma.

Our previously published results showed that growth factors and their receptors were frequently overexpressed in human SCC (19). To determine if these proteins were overexpressed in mouse SCC and spindle cell carcinoma we examined EGFR, TGF $\alpha$, met, and HGF by immunohistochemistry. As shown in Fig. 4, mouse SCC overexpressed both growth factor receptors and their ligands. Approximately $40 \%$ of SCCs overexpressed EGFR compared to none of the spindle cell carcinomas $(\mathrm{p}<0.01)$. Approximately $50 \%$ of SCCs overexpressed met while this protein was not detected in any of the spindle cell carcinomas $(\mathrm{p}<0.02)$. TGF $\alpha$ and HGF proteins were overexpressed in $80 \%$ of SCCs but not in any cases of spindle cell carcinoma $(p<0.01)$. These results indicate that loss of growth factor receptors and their ligands is a common feature of spindle cell carcinomas.

We also examined expression of p53, c-myc, TERT, and PCNA in mouse SCCs and spindle cell carcinomas. While p53 protein was detected in $90 \%$ of SCCs, we did not detect its expression in spindle cell carcinomas ( $<<0.001$; Fig. 5). c-myc protein was detected in approximately $30 \%$ of SCCs

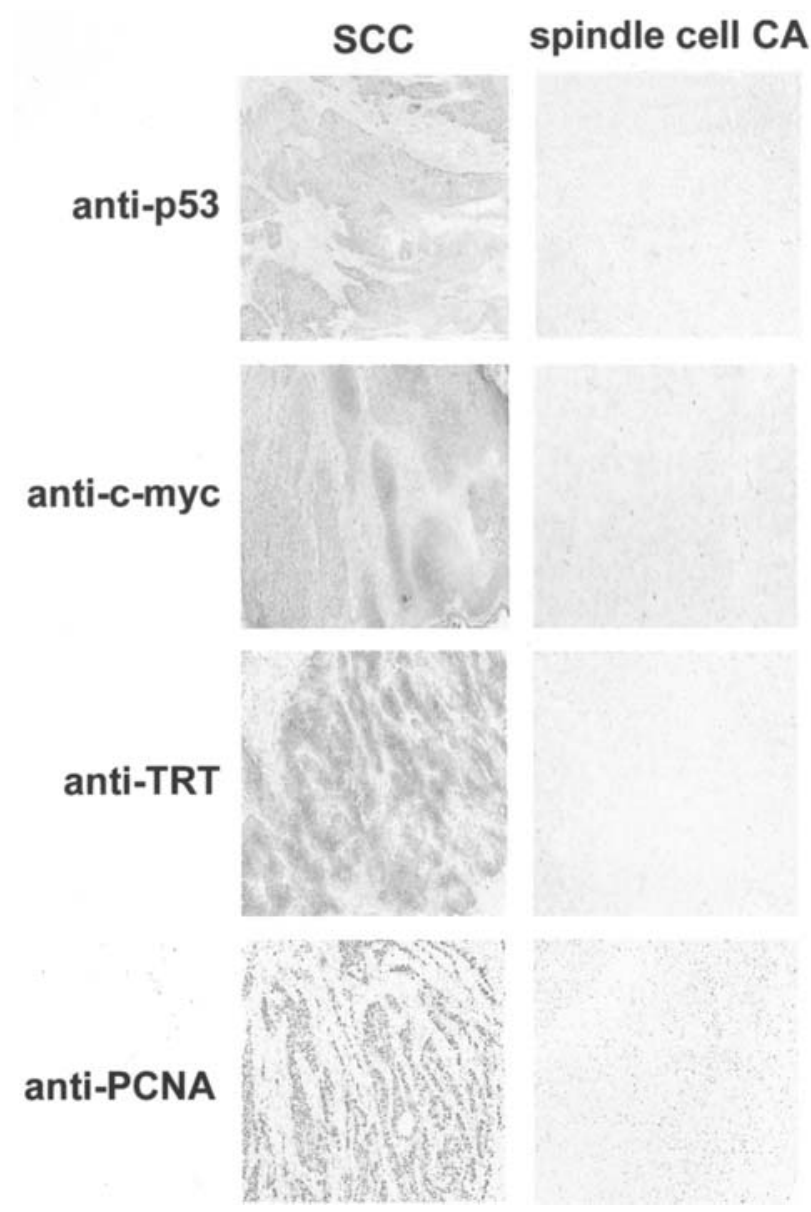

Figure 5. Loss of p53, c-myc, mTERT, and PCNA protein expression in spindle cell carcinoma. Expression of these proteins is shown by immunohistochemistry. These experiments were performed three times with different SCC and spindle cell carcinoma samples with similar results. Representative sections are shown.

but none of the spindle cell carcinomas $(\mathrm{p}<0.05)$. TERT was detected to variable extent in all SCCs but not in spindle cell carcinomas $(\mathrm{p}<0.001)$. PCNA expression was detected to variable extent in all SCCs but not in spindle cell carcinomas $(\mathrm{p}<0.001)$. Taken together, these results indicate that spindle cell carcinomas do not overexpress growth factor receptors, ligands, cell cycle regulatory proteins, and tumor suppressors normally found in human and mouse SCCs.

Our immunohistochemical data indicated that spindle cell carcinomas were substantially different with regard to genes commonly overexpressed in SCCs. To better understand the genetic differences between SCCs and spindle cell carcinomas, we used microarray analysis to globally profile gene expression. As shown in Fig. 6A, 91 genes were upregulated and 73 genes were downregulated when well-differentiated and moderatelydifferentiated SCCs were compared. In contrast, 919 genes were upregulated and 202 genes were downregulated when well-differentiated SCC was compared to spindle cell carcinoma. Similarly, 870 genes were upregulated and 423 genes were downregulated when moderately-differentiated SCC was compared to spindle cell carcinoma. Dendrogram analysis revealed that well and moderately-differentiated SCCs were highly related to each other by gene expression profile while spindle cell carcinoma was distantly related to 
A

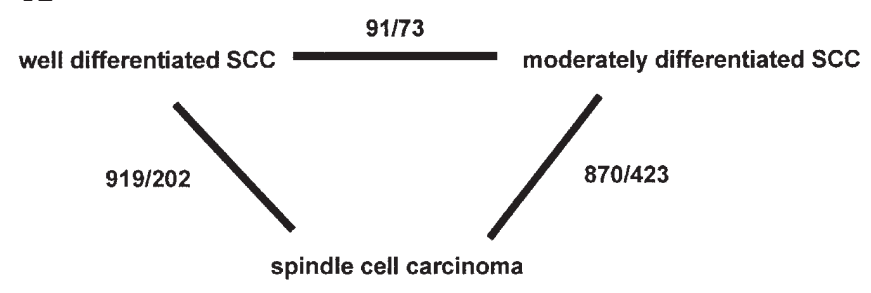

B

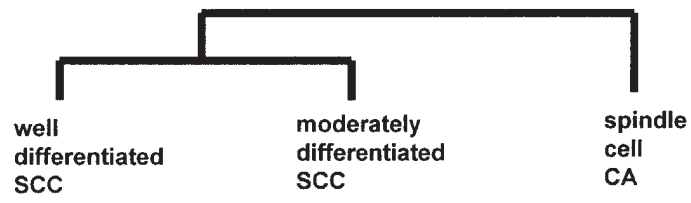

Figure 6 . The gene expression signature of spindle cell carcinoma is distinctly different from squamous cell carcinoma. (A), Numbers of differentially expressed genes when well-differentiated SCC, moderately-differentiated SCC, and spindle cell carcinoma are compared. The left number in each set is the number of upregulated differentially expressed genes and the right number reflects downregulated genes. (B), Hierarchical clustering analysis of SCCs and spindle cell carcinoma gene expression signatures. Spindle cell carcinoma (CA) is only distantly related by gene expression signature to well- and moderately-differentiated SCC.

SCCs (Fig. 6B). Gene expression changes between well- and moderately-differentiated SCC are shown in Table I. Gene expression changes between these two cancers and spindle cell carcinoma are shown in Tables II and III. Spindle cell carcinoma was characterized by marked downregulation of stratified squamous epithelial terminal differentiation markers such as the group of small proline rich proteins, loricrin, transglutaminase, and involucrin. Expression of a large number of keratin genes which are markers of epithelial differentiation was also dramatically inhibited in spindle cell carcinoma. Levels of cellular adhesion genes were substantially downregulated in spindle cell carcinoma including desmogleins $1 \alpha$ and $B$, cadherin 1 , plakophilin 3, desmocollins 2 and 3 , and desmoplakin. Expression of growth factors and receptors important for epithelial proliferation was inhibited, namely transforming growth factor $\alpha$, amphiregulin, and the EGFR family member Erbb3. By contrast, expression of growth factors and receptors important in fibroblast and mesenchymal cell proliferation was enhanced including transforming growth factor $\beta$ receptors type II and III, bone morphogenetic protein 4 , and insulin like growth factor 1. Expression of a number of proteinase inhibitors was downregulated (serpins A3, B3A, B3B, B5, B6C, B12) while protease expression (matrix metalloproteinase 2, serine protease 35 ) was increased in spindle cell carcinomas. By far the largest class of upregulated genes in spindle cell carcinomas was chemokine receptors and ligands which are involved in tumor cell invasion and metastasis. These changes in gene expression clearly show loss of epithelial characteristics, acquisition of mesenchymal phenotypes, and increased propensity for invasion and metastasis by spindle cell carcinomas.

\section{Discussion}

Little is known about the genetic differences between SCC and spindle cell carcinoma. Examination of these differences may provide important information about anaplastic progression, clinical behavior, and response to chemotherapy. We created a mouse model in which spindle cell carcinoma occurs in $10 \%$ of animals. These tumors were composed of sheets and bundles of spindle shaped cells with elongated nuclei and loss of intercellular junctions. Eosinophilic inclusions were frequently observed in the cytoplasm of these cells which likely represented abnormal keratin production; mitotic figures were rarely observed in these tumors. Consistent with this histopathology, spindle cell carcinoma was characterized by marked downregulation of stratified squamous epithelial terminal differentiation markers such as the group of small proline rich proteins, loricrin, transglutaminase, and involucrin. Expression of a large number of keratin genes which are markers of epithelial differentiation was also dramatically inhibited in spindle cell carcinoma. Levels of cell adhesion genes were substantially downregulated in spindle cell carcinoma including desmogleins $1 \alpha$ and $\beta$, cadherin 1 , plakophilin 3, desmocollins 2 and 3, and desmoplakin. These results indicate substantial loss of epithelial characteristics in spindle cell carcinomas.

Further evidence of major differences between SCC and spindle cell carcinoma was observed when examining expression of gene products normally overexpressed in human SCC. SCCs overexpressed cyclins A, B, and E as shown by immunohistochemistry. However, spindle cell carcinomas did not overexpress any of these cyclins. Similarly SCCs overexpressed EGFR and met and their ligands TGF $\alpha$ and HGF compared to none of the spindle cell carcinomas. Downregulation of these and other epithelial growth factors and receptors also were noted in gene expression profiling studies of spindle cell carcinomas. By contrast, expression of growth factors and receptors important in fibroblast and mesenchymal cell proliferation was enhanced including transforming growth factor $\beta$ receptors type II and III, bone morphogenetic protein 4 , and insulin like growth factor 1 . These results indicate that proliferation of SCCs and spindle cell carcinomas is regulated by markedly different sets of growth factors.

Spindle cell carcinomas were characterized by striking upregulation of chemokine ligands and receptors. Chemokine receptors are involved in breast cancer metastasis, in particular CXCR4, CXCR2, CCR7, and CCR8 (20). In future experiments, it will be important to determine the role of chemokine receptors in spindle cell carcinoma progression, proliferation, and metastasis. Expression of a number of proteinase inhibitors was downregulated while protease expression was increased in spindle cell carcinomas. Additionally, expression of transmembrane gene products semaphorins and mesothelin was upregulated in spindle cell carcinomas. Both of these proteins have been implicated in tumor progression and metastasis $(21,22)$. Both in vitro and in vivo experiments will be required to determine if spindle cell carcinomas are more invasive and metastatic compared to SCC.

While spindle cell carcinoma has been recognized as a distinct histopathologic entity, the role of epithelialmesenchymal transition in neoplasia has been debated recently 
Table I. Gene expression changes between well- and moderately-differentiated SCC.

\begin{tabular}{|c|c|c|c|}
\hline Accession & Symbol & Gene name & Fold change \\
\hline NM_007606 & Car3 & Carbonic anhydrase 3 & -13.2 \\
\hline AW208573 & Ace & Angiotensin converting enzyme & -10.4 \\
\hline AU020421 & D13Ertd787e & DNA segment, Chr 13, ERATO Doi 787, expressed & -7.8 \\
\hline BB542051 & Ogn & Osteoglycin & -7.7 \\
\hline NM_010783 & Mdfi & MyoD family inhibitor & -7.0 \\
\hline NM_053094 & $\mathrm{Cd} 163$ & CD163 antigen & -7.0 \\
\hline NM_008987 & Ptx3 & Pentraxin related gene & -6.7 \\
\hline BG075165 & Igf1 & Insulin-like growth factor 1 & -6.6 \\
\hline BB811478 & Npm3 & Nucleoplasmin 3 & -6.3 \\
\hline U89924 & Ppp1r3c & Protein phosphatase 1, regulatory (inhibitor) subunit 3C & -6.3 \\
\hline NM_016933 & Ptprcap & Protein tyrosine phosphatase, $\mathrm{C}$ polypeptide-associated protein & -6.0 \\
\hline NM_008571 & Mcpt2 & Mast cell protease 2 & -5.9 \\
\hline BB126310 & Plscr4 & Phospholipid scramblase 4 & -5.9 \\
\hline NM_013553 & Hoxc4 & Homeo box $\mathrm{C} 4$ & -5.9 \\
\hline BB770932 & Apcdd 1 & Adenomatosis polyposis coli down-regulated 1 & -5.8 \\
\hline NM_013467 & Aldh1a1 & Aldehyde dehydrogenase family 1 , subfamily A1 & -5.5 \\
\hline AA386586 & Hoxb9 & Homeo box B9 & -5.2 \\
\hline BB440143 & Hoxc6 & Homeo box C6 & -5.1 \\
\hline NM_009780 & $\mathrm{C} 4$ & Complement component 4 (within $\mathrm{H}-2 \mathrm{~S}$ ) & -5.1 \\
\hline NM_008489 & Lbp & Lipopolysaccharide binding protein & -5.1 \\
\hline NM_029838 & Col25a1 & Procollagen, type XXV, alpha 1 & -5.1 \\
\hline AW556888 & Ddah1 & Dimethylarginine dimethylaminohydrolase 1 & -5.0 \\
\hline NM_009724 & Atp4b & ATPase, $\mathrm{H}^{+} / \mathrm{K}^{+}$transporting, beta polypeptide, gastric specific & -5.0 \\
\hline AV 304251 & Marcks & Myristoylated alanine rich protein kinase $\mathrm{C}$ substrate & -5.0 \\
\hline NM_012043 & Islr & Immunoglobulin superfamily containing leucine-rich repeat & -4.9 \\
\hline NM_021532 & Dact1 & Dapper homolog 1, antagonist of beta-catenin (xenopus) & -4.9 \\
\hline AK004371 & Rasl11a & RAS-like, family 11 , member A & -4.7 \\
\hline NM_009472 & Unc5c & Unc-5 homolog $\mathrm{C}(C$. elegans $)$ & -4.7 \\
\hline BQ176063 & Srrm2 & Serine/arginine repetitive matrix 2 & -4.6 \\
\hline AV228731 & Adamts 15 & A disintegrin-like and metalloprotease, thrombospondin type 1 motif 15 & -4.6 \\
\hline BB250384 & Vcam1 & Vascular cell adhesion molecule 1 & -4.5 \\
\hline NM_053134 & Pcdhb9 & Protocadherin beta 9 & -4.2 \\
\hline AY035889 & Tlr7 & Toll-like receptor 7 & -4.2 \\
\hline AK018504 & Rassf2 & Ras association (RalGDS/AF-6) domain family 2 & -4.2 \\
\hline ВC013068 & Pcsk5 & Proprotein convertase subtilisin/kexin type 5 & -4.2 \\
\hline BB548889 & Gpr133 & G protein-coupled receptor 133 & -4.2 \\
\hline AA051236 & Hoxc5 & Homeo box C5 & -4.2 \\
\hline NM_021443 & $\mathrm{Ccl} 8$ & Chemokine (C-C motif) ligand 8 & -4.1 \\
\hline BB541289 & Hspa4 & Heat shock protein 4 & -4.1 \\
\hline AK003894 & Glt8d2 & Glycosyltransferase 8 domain containing 2 & -4.1 \\
\hline ВС001991 & Sepp1 & Selenoprotein P, plasma, 1 & -4.1 \\
\hline BB010894 & Matp & Membrane associated transporter protein & -4.0 \\
\hline AW550625 & Col3a1 & Procollagen, type III, alpha 1 & -3.8 \\
\hline BB076855 & Ptbp2 & Polypyrimidine tract binding protein 2 & -3.8 \\
\hline BB037068 & Klhl4 & Kelch-like 4 (Drosophila) & -3.8 \\
\hline BB756069 & Tfpi & Tissue factor pathway inhibitor & -3.7 \\
\hline AI326167 & Bcl2ala & B-cell leukemia/lymphoma 2 related protein A1a & -3.7 \\
\hline BB338441 & Matn2 & Matrilin 2 & -3.7 \\
\hline AV270881 & Zfp597 & Zinc finger protein 597 & -3.7 \\
\hline NM_008110 & Gdf9 & Growth differentiation factor 9 & -3.7 \\
\hline $\mathrm{BC} 027120$ & Tram111 & Translocation associated membrane protein 1 -like 1 & -3.7 \\
\hline AK014135 & Clec4a3 & C-type lectin domain family 4, member a3 & -3.6 \\
\hline AW049748 & Plcb1 & Phospholipase $\mathrm{C}$, beta 1 & -3.1 \\
\hline NM_007909 & Efna2 & Ephrin A2 & -2.9 \\
\hline $\mathrm{AF} 024638$ & Fgfr3 & Fibroblast growth factor receptor 3 & -2.9 \\
\hline BB211471 & Cryzl1 & Crystallin, zeta (quinone reductase)-like 1 & 5.4 \\
\hline BB526119 & Bcl11a & B-cell CLL/lymphoma 11A (zinc finger protein) & 5.6 \\
\hline NM_011478 & Sprr3 & Small proline-rich protein 3 & 10.0 \\
\hline
\end{tabular}


Table II. Gene expression changes between well-differentiated SCC and spindle cell carcinoma.

\begin{tabular}{|c|c|c|c|}
\hline Accession & Symbol & Gene name & Fold change \\
\hline NM_033175 & Sprrl1 & Small proline rich-like 1 & -322.1 \\
\hline AV241297 & Spink5 & Serine protease inhibitor, Kazal type 5 & -87.6 \\
\hline NM_011472 & Sprr2f & Small proline-rich protein $2 \mathrm{~F}$ & -79.7 \\
\hline ВС016507 & Gjb6 & Gap junction membrane channel protein beta 6 & -78.8 \\
\hline NM_013756 & Defb3 & Defensin beta 3 & -76.9 \\
\hline NM_011476 & Sprr $2 j$ & Small proline-rich protein $2 \mathrm{~J}$ & -73.1 \\
\hline ВC024380 & Defb1 & Defensin beta 1 & -59.4 \\
\hline NM_008182 & Gsta1 & Glutathione S-transferase, alpha 1 (Ya) & -55.6 \\
\hline NM_011475 & Sprr2i & Small proline-rich protein 2I & -46.3 \\
\hline AK009018 & Serpinb12 & Serine (or cysteine) proteinase inhibitor, clade B, member 12 & -45.5 \\
\hline AW048300 & Fath2 & Fat tumor suppressor homolog 2 (Drosophila) & -41.5 \\
\hline NM_011474 & Sprr2h & Small proline-rich protein $2 \mathrm{H}$ & -35.0 \\
\hline NM_009264 & Sprr1a & Small proline-rich protein $1 \mathrm{~A}$ & -34.2 \\
\hline BB699605 & Serpinb3a & Serine (or cysteine) proteinase inhibitor, clade B, member $3 \mathrm{~A}$ & -33.4 \\
\hline NM_008508 & Lor & Loricrin & -33.0 \\
\hline NM_010662 & Krt1-13 & Keratin complex 1 , acidic, gene 13 & -31.3 \\
\hline NM_008475 & Krt2-4 & Keratin complex 2, basic, gene 4 & -29.9 \\
\hline NM_009126 & Serpinb3b & Serine (or cysteine) proteinase inhibitor, clade B member 3B & -27.3 \\
\hline NM_011470 & Sprr2d & Small proline-rich protein $2 \mathrm{D}$ & -27.2 \\
\hline AI893889 & $\operatorname{Tgm} 3$ & Transglutaminase 3 , E polypeptide & -27.1 \\
\hline AV253195 & Dsg1b & Desmoglein 1 beta & -23.7 \\
\hline NM_009864 & Cdh1 & Cadherin 1 & -21.5 \\
\hline AK009778 & Xrcc1 & $\mathrm{X}$-ray repair complementing defective repair in Chinese hamster & -21.0 \\
\hline AF425084 & Serpinb6c & Serine (or cysteine) proteinase inhibitor, clade B, member $6 \mathrm{c}$ & -20.6 \\
\hline AI462524 & Serpinb5 & Serine (or cysteine) proteinase inhibitor, clade B, member 5 & -18.6 \\
\hline AA798563 & Krt1-17 & Keratin complex 1 , acidic, gene 17 & -18.2 \\
\hline NM_019956 & Krt2-6g & Keratin complex 2 , basic, gene $6 \mathrm{~g}$ & -16.3 \\
\hline AW475993 & Pkp3 & Plakophilin 3 & -15.7 \\
\hline NM_009523 & Wnt4 & Wingless-related MMTV integration site 4 & -14.6 \\
\hline $\mathrm{BC} 004663$ & Dsc2 & Desmocollin 2 & -14.4 \\
\hline BB151286 & Dsg1a & Desmoglein 1 alpha & -13.3 \\
\hline NM_013504 & Dsc1 & Desmocollin 1 & -10.2 \\
\hline BE197934 & Krt1-14 & Keratin complex 1 , acidic, gene 14 & -9.4 \\
\hline NM_009522 & Wnt3a & Wingless-related MMTV integration site $3 \mathrm{~A}$ & -9.2 \\
\hline $\mathrm{BC} 006780$ & Krt2-5 & Keratin complex 2, basic, gene 5 & -9.0 \\
\hline NM_008470 & Krt1-16 & Keratin complex 1 , acidic, gene 16 & -8.8 \\
\hline C7995 & Dsg2 & Desmoglein 2 & -8.8 \\
\hline ВC026631 & Dsp & Desmoplakin & -8.2 \\
\hline Y11169 & Dsc3 & Desmocollin 3 & -7.4 \\
\hline M92420 & Tgfa & Transforming growth factor alpha & -7.1 \\
\hline BB296763 & Tgfb2 & Transforming growth factor, beta 2 & -6.8 \\
\hline NM_008412 & Ivl & Involucrin & -6.7 \\
\hline $\mathrm{BF} 140685$ & Erbb3 & v-erb-b2 erythroblastic leukemia viral oncogene homolog 3 (avian) & -6.4 \\
\hline AK014360 & Krt1-10 & Keratin complex 1 , acidic, gene 10 & -6.2 \\
\hline NM_011337 & $\mathrm{Ccl} 3$ & Chemokine (C-C motif) ligand 3 & 5.1 \\
\hline NM_013653 & $\mathrm{Ccl} 5$ & Chemokine (C-C motif) ligand 5 & 5.1 \\
\hline AF128193 & $\mathrm{Ccl} 7$ & Chemokine (C-C motif) ligand 7 & 5.4 \\
\hline X94151 & Ccr5 & Chemokine (C-C motif) receptor 5 & 5.6 \\
\hline S69114 & Tgfbr2 & Transforming growth factor, beta receptor II & 5.7 \\
\hline AK016527 & Cdh13 & Cadherin 13 & 5.8 \\
\hline ВC012653 & $\mathrm{Cx} 3 \mathrm{cr} 1$ & Chemokine $(\mathrm{C}-\mathrm{X} 3-\mathrm{C})$ receptor 1 & 5.9 \\
\hline BB499147 & Sema3d & Sema domain, short basic domain, secreted, (semaphorin) 3D & 6.6 \\
\hline NM_009152 & Sema3a & Sema domain, short basic domain, secreted, (semaphorin) 3A & 6.6 \\
\hline NM_013655 & $\mathrm{Cxcl12}$ & Chemokine (C-X-C motif) ligand 12 & 7.8 \\
\hline NM_019932 & $\mathrm{Cxcl} 4$ & Chemokine (C-X-C motif) ligand 4 & 7.9 \\
\hline $\mathrm{BC} 012653$ & $\mathrm{Cx} 3 \mathrm{cr} 1$ & Chemokine $(\mathrm{C}-\mathrm{X} 3-\mathrm{C})$ receptor 1 & 14.1 \\
\hline U50712 & $\mathrm{Ccl1} 2$ & Chemokine (C-C motif) ligand 12 & 20.1 \\
\hline NM_018857 & Msln & Mesothelin & 34.7 \\
\hline
\end{tabular}


Table III. Gene expression changes between moderately-differentiated SCC and spindle cell carcinoma.

\begin{tabular}{|c|c|c|c|}
\hline Accession & Symbol & Gene name & Fold change \\
\hline NM_008475 & Krt2-4 & Keratin complex 2, basic, gene 4 & -289.1 \\
\hline NM_010662 & Krt1-13 & Keratin complex 1 , acidic, gene 13 & -238.3 \\
\hline NM_033175 & Sprrl1 & Small proline rich-like 1 & -208.3 \\
\hline AK009018 & Serpinb12 & Serine (or cysteine) proteinase inhibitor, clade B member 12 & -103.2 \\
\hline NM_011478 & Sprr3 & Small proline-rich protein 3 & -102.3 \\
\hline NM_008508 & Lor & Loricrin & -96.3 \\
\hline NM_009126 & Serpinb3b & Serine (or cysteine) proteinase inhibitor, clade B member 3B & -47.7 \\
\hline BB699605 & Serpinb3a & Serine (or cysteine) proteinase inhibitor, clade B member 3A & -43.2 \\
\hline NM_008182 & Gsta1 & Glutathione S-transferase, alpha 1 (Ya) & -42.7 \\
\hline NM_011476 & Sprr $2 \mathrm{j}$ & Small proline-rich protein $2 \mathrm{~J}$ & -42.2 \\
\hline NM_028625 & Sprrl2 & Small proline rich-like 2 & -40.7 \\
\hline $\mathrm{X} 84014$ & Lama3 & Laminin, alpha 3 & -40.5 \\
\hline AI893889 & $\operatorname{Tgm} 3$ & Transglutaminase 3 , E polypeptide & -36.8 \\
\hline NM_011475 & Sprr2i & Small proline-rich protein $2 \mathrm{I}$ & -36.7 \\
\hline NM_009264 & Sprr1a & Small proline-rich protein $1 \mathrm{~A}$ & -34.1 \\
\hline AW475993 & Pkp3 & Plakophilin 3 & -28.0 \\
\hline AK009778 & Xrcc1 & $\mathrm{X}$-ray repair complementing defective repair 1 & -28.0 \\
\hline NM_026822 & Sprrl5 & Small proline rich-like 5 & -26.4 \\
\hline AW322280 & Krt2-8 & Keratin complex 2 , basic, gene 8 & -17.6 \\
\hline ВC026422 & Tgm1 & Transglutaminase 1 , K polypeptide & -17.5 \\
\hline NM_019956 & Krt2-6g & Keratin complex 2, basic, gene $6 \mathrm{~g}$ & -17.5 \\
\hline NM_009864 & Cdh1 & Cadherin 1 & -17.3 \\
\hline AV253195 & Dsg1b & Desmoglein 1 beta & -16.5 \\
\hline NM_013504 & Dsc1 & Desmocollin 1 & -14.6 \\
\hline NM_009523 & Wnt4 & Wingless-related MMTV integration site 4 & -12.4 \\
\hline AK004683 & Wnt7a & Wingless-related MMTV integration site 7A & -11.6 \\
\hline M92420 & Tgfa & Transforming growth factor alpha & -11.4 \\
\hline NM_009704 & Areg & Amphiregulin & -11.2 \\
\hline $\mathrm{BF} 140685$ & Erbb3 & v-erb-b2 erythroblastic leukemia viral oncogene homolog 3 (avian) & -10.2 \\
\hline ВC006780 & Krt2-5 & Keratin complex 2 , basic, gene 5 & -9.3 \\
\hline ВC026631 & Dsp & Desmoplakin & -9.2 \\
\hline NM_008412 & Ivl & Involucrin & -7.8 \\
\hline BE197934 & Krt1-14 & Keratin complex 1 , acidic, gene 14 & -6.9 \\
\hline NM_008470 & Krt1-16 & Keratin complex 1 , acidic, gene 16 & -6.1 \\
\hline AK014360 & Krt1-10 & Keratin complex 1 , acidic, gene 10 & -5.3 \\
\hline S69114 & Tgfbr2 & Transforming growth factor, beta receptor II & 5.0 \\
\hline BB148128 & Ccr2 & Chemokine (C-C motif) receptor 2 & 5.5 \\
\hline AF128196 & $\mathrm{Ccl} 9$ & Chemokine (C-C motif) ligand 9 & 5.8 \\
\hline AF065933 & $\mathrm{Ccl} 2$ & Chemokine (C-C motif) ligand 2 & 6.0 \\
\hline NM_007554 & Bmp4 & Bone morphogenetic protein 4 & 6.2 \\
\hline NM_011888 & Ccl19 & Chemokine (C-C motif) ligand 19 & 6.3 \\
\hline NM_008610 & Mmp2 & Matrix metalloproteinase 2 & 7.2 \\
\hline NM_019932 & Cxcl4 & Chemokine (C-X-C motif) ligand 4 & 7.5 \\
\hline NM_013653 & $\mathrm{Ccl} 5$ & Chemokine (C-C motif) ligand 5 & 7.5 \\
\hline AF128193 & $\mathrm{Ccl} 7$ & Chemokine (C-C motif) ligand 7 & 7.8 \\
\hline X94151 & Ccr5 & Chemokine (C-C motif) receptor 5 & 7.9 \\
\hline AF030636 & Cxcl13 & Chemokine (C-X-C motif) ligand 13 & 8.8 \\
\hline NM_018857 & Msln & Mesothelin & 9.3 \\
\hline AF039601 & Tgfbr3 & Transforming growth factor, beta receptor III & 10.1 \\
\hline NM_013655 & $\mathrm{Cxcl} 12$ & Chemokine (C-X-C motif) ligand 12 & 11.2 \\
\hline $\mathrm{BC} 012653$ & $\mathrm{Cx} 3 \mathrm{cr} 1$ & Chemokine $(\mathrm{C}-\mathrm{X} 3-\mathrm{C})$ receptor 1 & 11.3 \\
\hline X94151 & Ccr5 & Chemokine (C-C motif) receptor 5 & 11.5 \\
\hline NM_011126 & Plunc & Palate, lung, and nasal epithelium carcinoma associated & 12.1 \\
\hline NM_021443 & $\mathrm{Ccl} 8$ & Chemokine (C-C motif) ligand 8 & 12.8 \\
\hline BG092677 & Igf1 & Insulin-like growth factor 1 & 23.8 \\
\hline BB042892 & Prss 35 & Protease, serine, 35 & 29.7 \\
\hline U50712 & $\mathrm{Ccl12}$ & Chemokine (C-C motif) ligand 12 & 33.1 \\
\hline NM_009144 & Sfrp2 & Secreted frizzled-related sequence protein 2 & 48.6 \\
\hline
\end{tabular}


$(23,24)$. Until now, global gene expression profiling of spindle cell carcinoma has not been undertaken. Our results show distinct gene expression profiles between SCC and spindle cell carcinoma. Future studies using this model system will contribute to the debate over epithelial-mesenchymal transition and help us to understand the genetic basis of tumor progression, proliferation, invasion, and metastasis in SCC and spindle cell carcinoma.

\section{Acknowledgements}

We thank Drs Tim Triche, Betty Schaub, and Sitara Waidyaratne (Genomics Core Facility, Children's Hospital, Los Angeles, CA) for assistance with microarray analysis. This study was supported by National Institutes of Health grant DE14283 to D.L.C.

\section{References}

1. Moore SR, Johnson NW, Pierce AM and Wilson DF: The epidemiology of mouth cancer: a review of global incidence. Oral Diseases 6: 65-74, 2000.

2. Goldberg HI, Lockwood SA, Wyatt SW and Crossett LS: Trends and differentials in mortality from cancers of the oral cavity and pharynx in the United States, 1973-1987. Cancer 74: 565-572, 1994.

3. Grandis JR, Pietenpol JA, Greenberger JS, Pelroy RA and Mohla S: Head and neck cancer: meeting summary and research opportunities. Cancer Res 64: 8126-8129, 2004.

4. Crowe DL, Hacia JG, Hsieh CL, Sinha UK and Rice DH: Molecular pathology of head and neck cancer. Histol Histopathol 17: 909-914, 2002.

5. Schwarz JL and Shklar G: Verification in syngeneic hamsters of in vitro transformation of hamster oral mucosa by 7,12dimethylbenz(a)anthracene. Oral Oncol 33: 431-438, 1997.

6. Rheinwald JG and Beckett MA: Tumorigenic keratinocyte lines requiring anchorage and fibroblast support cultures from human squamous cell carcinomas. Cancer Res 41: 1657-1663, 1981.

7. Kawashiri S, Kumagai S, Kojima K, Harada H, Nakagawa K and Yamamoto E: Reproduction of occult metastasis of head and neck cancer in nude mice. Clin Exp Metastasis 17: 277-282, 1999.

8. Simon C, Hicks MJ, Nemechek AJ, Mehta R, O'Malley BW, Goepfert H, Flaitz CM and Boyd D: PD98059, an inhibitor of ERK1 activation, attenuates the in vivo invasiveness of head and neck squamous cell carcinoma. Br J Cancer 80: 1412-1419, 1999.
9. Caulin C, Nguyen T, Longley MA, Zhou Z, Wang XJ and Roop DR: Inducible activation of oncogenic K-ras results in tumor formation in the oral cavity. Cancer Res 64: 5054-5058, 2004.

10. Vitale-Cross L, Amornphimoltham P, Fisher G, Molinolo AA and Gutkind JS: Conditional expression of K-ras in an epithelial compartment that includes stem cells is sufficient to promote squamous cell carcinogenesis. Cancer Res 64: 8804-8807, 2004.

11. Saranath D, Chang SE, Bhoite LT, Panchal RG, Kerr IB, Mehta AR, Johnson NW and Deo MG: High frequency mutation in codons 12 and 61 of H-ras oncogene in chewing tobacco related human oral carcinoma in India. Br J Cancer 63: 573-578, 1991.

12. Munirajan AK, Mohanprasad BK, Shanmugam G and Tsuchida N: Detection of a rare point mutation at codon 59 and relatively high incidence of H-ras mutation in Indian oral cancer. Int J Oncol 13: 971-974, 1998.

13. Ampil FL: The controversial role of radiotherapy in spindle cell carcinoma (pseudosarcoma) of the head and neck. Radiat Med 3: 225-229, 1985 .

14. Benninger MS, Kraus D, Sebek B, Tucker HM and Lavertu P Head and neck spindle cell carcinoma: an evaluation of current management. Cleve Clin J Med 59: 479-482, 1992.

15. Zarbo RJ, Crissman JD, Venkat H and Weiss MA: Spindle cell carcinoma of the upper aerodigestive tract mucosa. Am J Surg Pathol 10: 741-753, 1986.

16. Ellis GL, Langloss JM, Heffner DK and Hyams VJ: Spindle cell carcinoma of the aerodigestive tract. Am J Surg Pathol 11: 335-342, 1987.

17. Durham JS, Nash J, Rothery G, Dalby JE and Stell PM: Anaplastic carcinoma presenting with cervical lymphadenopathy. Clin Otolaryngol 15: 529-534, 1990.

18. Furusaka T, Kida A, Aoyagi M, Makiyama K, Iida H, Miyakogawa M, Kikuchi K and Tomita H: CAP therapy for advanced, recurrent and/or metastatic malignant tumors of the head and neck. Auris Nasus Larynx 13: S119-S126, 1986.

19. Nguyen DC, Parsa B, Close A, Magnusson B, Crowe DL and Sinha UK: Overexpression of cell cycle regulatory proteins correlates with advanced tumor stage in head and neck squamous cell carcinomas. Int J Oncol 22: 1285-1290, 2003.

20. Muller A, Homey B, Soto H, et al: Involvement of chemokine receptors in breast cancer metastasis. Nature 410: 50-56, 2001.

21. Kruger RP, Aurandt J and Guan KL: Semaphorins command cells to move. Nat Rev Mol Cell Biol 6: 789-800, 2005.

22. Onda M, Willingham M, Nagata S, Bera TK, Beers R, Ho M, Hassan R, Kreitman RJ and Pastan I: New monoclonal antibodies to mesothelin useful for immunohistochemistry, fluorescence activated cell sorting, western blotting, and ELISA. Clin Cancer Res 11: 5840-5846, 2005.

23. Tarin D: The fallacy of epithelial mesenchymal transition in neoplasia. Cancer Res 65: 5996-6001, 2005.

24. Thompson EW and Newgreen DF: Carcinoma invasion and metastasis: a role for epithelial-mesenchymal transition? Cancer Res 65: 5991-5995, 2005. 